Thorax 1989;44:303-304

Short report

\title{
Clinical and radiographic study of activated carbon workers
}

\section{G URAGODA \\ From the Central Chest Clinic, Colombo, Sri Lanka}

ABSTRACT Activated carbon is made in Sri Lanka by passing steam through charcoal made from coconut shells. The carbon does not contain free silica. Sixty six men who had worked in a factory making activated carbon for an average of $\mathbf{7 . 2}$ years had no more respiratory symptoms than a control group, and none showed radiological evidence of pneumoconiosis. There was no evidence that people exposed to charcoal and pure carbon for up to 11 years are at risk of developing pneumoconiosis.

Activated carbon has various uses, including the removal of undesirable tastes and smells, purification of air and water, clarification of alcoholic drinks, and the treatment of sewage. It is made from charcoal obtained by carbonisation of such materials as wood, peat, lignite, and coal. In Sri Lanka coconut shells are mainly used. These are burnt in a pit in the ground and before they are reduced to ash the pit is covered usually by metal sheets and earth. When it is opened several days later charcoal is obtained.

Charcoal contains countless microscopic pores but these are blocked by tarry material or amorphous carbon. Activated carbon is obtained when these pores are cleared by oxidation of the blocking material, and steam may be used to do this. The process exposes workers to carbon dust. The present study was designed to assess the frequency of respiratory symptoms and radiographic abnormalities in the employees of a factory preparing activated carbon.

\section{The factory}

The factory manufactured 2500 metric tons of activated carbon annually for export, and was the only one of its kind in Sri Lanka at the time the study was conducted. All the manufacturing processes were carried out in a high roofed building open on three sides. It was situated in the richest coconut growing area in the country. Charcoal made out of coconut shells was obtained from suppliers. It was sent to the factory, packed in gunny bags, and stacked in the factory until required.

Address for reprint requests: Dr C G Uragoda, 385 Deans Road, Colombo 10, Sri Lanka.

Accepted 2 December 1988
After removal of impurities the charcoal was crushed into small pieces by passage through rollers. These were fed into brick lined rotating kilns and fired with furnace oil to a temperature of $510-540^{\circ} \mathrm{C}$. At the same time steam was introduced as the activating agent. The reaction was allowed to proceed for eight hours. The activated carbon thus obtained was crushed to the required size and sifted into different grades. The finished product was then fed into steel hoppers for packing into multi-ply paper sacks.

Considerable amounts of dust were liberated from all these processes except the activation process, in which dust did not escape from the kilns. The concentration of dust particles was measured in the factory in July 1987 by cascade impactor. At $1.5 \mathrm{~m}$ above the ground the concentration of particles of less than $12.5 \mu \mathrm{m}$ was $17.5 \mathrm{mg} / \mathrm{m}^{3}$. The concentrations of particles of $12 \cdot 5-3 \cdot 5,3 \cdot 5-1 \cdot 2$, and $>1 \cdot 2 \mu \mathrm{m}$ were $14 \cdot 7,2 \cdot 03$, and $0.77 \mathrm{mg} / \mathrm{m}^{3}$. There was no proper system of dust extraction at the time the study was conducted, though modern equipment has since been installed. The employees worked an eight hour day and were frequently moved from one section to another within the factory.

\section{Methods}

All the workers engaged in activation and packing at the plant were admitted to the study. Supervisory staff and other ancillary workers not exposed to the dust were excluded.

The workers were examined at the Central Chest Clinic, Colombo. They were interviewed according to a questionnaire based on that of the Medical Research Council' but modified to suit local conditions. They underwent a clinical examination and had a chest radiograph on standard size film. Peak expiratory flow rates were measured with a mini Wright peak flow meter and compared with normal values. ${ }^{2}$ A control group consisting of workers in a motor engineering firm was examined in a similar way.

Radiographs of both groups were submitted to two radiologists, who independently evaluated them using the ILO international classification of radiographs of pneumoconioses. ${ }^{3}$

\section{Results}

Sixty six workers, all men aged $24-45$ (mean 33 ) years, were admitted to the study. Their employment in the factories ranged from one to 11 (mean 7.2) years (table). The 30 current smokers smoked one to 20 (mean 3) cigarettes a day. Ten workers had respiratory symptoms-wheeze in four subjects, cough in four, and chest pain in two. One worker aged 45 years, who smoked four cigarettes a day, had chronic 
Duration of employment of the 66 workers in the activated carbon factory

\begin{tabular}{lc}
\hline Period of work $(y)$ & $n$ \\
\hline $1-2$ & 2 \\
$3-4$ & 11 \\
$5-6$ & 14 \\
$7-8$ & 15 \\
$9-10$ & 15 \\
$11-12$ & 9 \\
Mean & $7 \cdot 2$ \\
\hline
\end{tabular}

bronchitis according to the Medical Research Council definition.' The only abnormal physical signs detected on clinical examination were bilateral rhonchi in two patients known to have asthma.

There was $100 \%$ agreement between the two readers on the radiographic findings. Two workers had abnormal radiographs. One, the man with chronic bronchitis, had small irregular opacities and the other had a pleural reaction at the right base. The other 64 radiographs were normal. Peak expiratory flow was within normal limits in all workers except the two with asthma and the one with chronic bronchitis.

The 56 workers in the control group were aged 26-48 (mean 35 ) years and again were all men. Nine had respiratory symptoms - cough in six, dyspnoea on exertion in three, wheeze in two, and chest pain in one. On the chest radiograph one had fibrotic changes in both lungs due to previously treated tuberculosis. Another, who gave a past history of a pleural effusion, had a raised right diaphragm.

The constituents of the activated carbon manufactured in the factory were fixed carbon $(92 \%)$, volatile matter $(4 \%)$, ash $(3 \%)$, and sulphur and chloride $(1 \%)$. The ash consisted of potassium, iodine, sodium, calcium, and magnesium. A notable feature was the absence of free silica.

\section{Discussion}

There has been debate about whether silica free carbon causes pneumoconiosis. None of these workers, who had had a relatively short exposure, had evidence of pneumoconiosis. The worker with chronic bronchitis, who had small irregulares opacities on the chest radiograph, was not considered to have pneumoconiosis as defined by Parkes. ${ }^{3}$ Wehr et al, ${ }^{5}$ however,듬 found that $10 \%$ of men making activated carbon from $\bar{\omega}$. charcoal obtained from lignite had rounded opacities of the $p_{\bar{\sigma}}$ type in the lower zones without evidence of coalescence. The lignite contained $0 \cdot 12 \%$ free silica but such a small amount of silica is unlikely to account for the difference in our findings. In another study Japanese workers reported three patients.whose chest radiograph had a fine ground glass appearance $; \overrightarrow{\vec{\omega}}$ the source material used in the production of the activated $\omega$ carbon, however, is not clear.

The workers studied here have had no more respiratory. symptoms than a control group. Carbon may be made $\overrightarrow{+}$ porous, however, by methods other than steam. Chemicalst such as metallic chlorides, phosphoric acid, caustic soda, and acids have been used and some of these may cause lunge damage.

I wish to thank Haycarb Limited and its medical officer, DrD S T Gunawardena, for their help.

\section{References}

1 Medical Research Council. Questionnaire on respiratory symptoms. 2nd ed. London: MRC, 1976.

2 Gregg I, Nunn AJ. Peak expiratory flow in normal subjects. $B r \precsim$ Med J 1973;iii:262-4.

3 Parkes WR. Occupational lung disorders. 2nd ed. London: Butter-을 worth, 1982:1.

4 International Labour Office. Guidelines for the use of the $I L O=$ international classification of radiographs of pneumoconioses. Geneva: ILO, 1980.

5 Wehr KL, Johanson WG, Chapman JS, Pierce AK. Pneumoconiosis among activated-carbon workers. Arch Environ Healt $\bar{h}$ 1975;30:578-82.

6 Saito Y, Chiyotani K, Saito K, et al. Functional, radiological and histological study of activated carbon pneumoconiosis. Journal of Japan Accident Medical Association 1978;12:948-54. 